\title{
Activin A triggers angiogenesis via regulation of VEGFA and its overexpression is associated with poor prognosis of oral squamous cell carcinoma
}

\author{
CARINE ERVOLINO DE OLIVEIRA ${ }^{1,2}$, MAURÍCIO ROCHA DOURADO ${ }^{1}$, ÍRIS SAWAZAKI-CALONE ${ }^{3}$, \\ MARCELL COSTA DE MEDEIROS ${ }^{4}$, CARLOS ROSSA JÚNIOR ${ }^{4}$, NILVA DE KARLA CERVIGNE ${ }^{5}$, \\ JORGE ESQUICHE LEÓN ${ }^{6}$, DANIEL LAMBERT ${ }^{7}$, TUULA SALO ${ }^{8,9}$, \\ EDGARD GRANER ${ }^{1}$ and RICARDO D. COLETTA ${ }^{1}$
}

\begin{abstract}
${ }^{1}$ Department of Oral Diagnosis, School of Dentistry, University of Campinas, Piracicaba, SP 13414-018; ${ }^{2}$ Department of Pathology and Parasitology, Federal University of Alfenas, Alfenas, MG 37130-001; ${ }^{3}$ Department of Oral Pathology and Oral Medicine, Dentistry School, Western Paraná State University, Cascavel, PR 85819-170; ${ }^{4}$ Departament of Diagnosis and Surgery, School of Dentistry at Araraquara, Araraquara, SP 14801-385; ${ }^{5}$ Clinical Department, Faculty of Medicine of Jundiai, Jundiai, SP 13202-550; ${ }^{6}$ Departament of Stomatology, Public Oral Health and Forensic Dentistry, School of Dentistry of

Ribeirão Preto, University of São Paulo, Ribeirão Preto, SP 14040-904, Brazil; ${ }^{7}$ Integrated Biosciences, School of Clinical Dentistry and Sheffield Cancer Centre, University of Sheffield, Sheffield S10 2TG, UK; ${ }^{8}$ Cancer and Translational Medicine Research Unit, Faculty of Medicine and Medical Research Center Oulu, Oulu University Hospital, University of Oulu, Oulu 90220; ${ }^{9}$ Institute of Oral and Maxillofacial Disease, University of Helsinki, and HUSLAB,

Department of Pathology, Helsinki University Hospital, Helsinki 00260, Finland
\end{abstract}

Received November 26, 2019; Accepted April 15, 2020

DOI: $10.3892 /$ ijo.2020.5058

\begin{abstract}
Poor prognosis associated with the dysregulated expression of activin $\mathrm{A}$ in a number of malignancies has been related to with numerous aspects of tumorigenesis, including angiogenesis. The present study investigated the prognostic significance of activin A immunoexpression in blood vessels and cancer cells in a number of oral squamous cell carcinoma (OSCC) cases and applied in vitro strategies to determine the impact of activin A on angiogenesis. In a cohort of 95 patients with OSCC, immunoexpression of activin A in both blood vessels and tumor cells was quantified and the association with clinicopathological parameters and survival was analyzed. Effects of activin A on the tube formation, proliferation and migration of human umbilical vein endothelial cells (HUVECs) were evaluated in gain-of-function (treatment with recombinant activin A) or loss-of-function [treatment with activin A-antagonist follistatin or by stable transfection with short hairpin RNA (shRNA) targeting activin A] conditions. Conditioned medium from an OSCC cell line
\end{abstract}

Correspondence to: Dr Carine Ervolino de Oliveira, Department of Pathology and Parasitology, Federal University of Alfenas, R. Gabriel Monteiro da Silva 700, Alfenas, MG 37130-001, Brazil E-mail: carineusp@yahoo.com.br

Key words: activin A, angiogenesis, vascular endothelial growth factor A, VEGFA121, prognosis, oral squamous cell carcinoma with shRNA-mediated depletion of activin A was also tested. The profile of pro- and anti-angiogenic factors regulated by activin A was assessed with a human angiogenesis quantitative PCR (qPCR) array. Vascular endothelial growth factor A (VEGFA) and its major isoforms were evaluated by reverse transcription-qPCR and ELISA. Activin A expression in blood vessels demonstrated an independent prognostic value in the multivariate analysis with a hazard ratio of 2.47 [95\% confidence interval (CI), 1.30-4.71; $\mathrm{P}=0.006)$ for disease-specific survival and 2.09 (95\% CI, 1.07-4.081: $\mathrm{P}=0.03$ ) for disease-free survival. Activin A significantly increased tubular formation of HUVECs concomitantly with an increase in proliferation. This effect was validated by reduced proliferation and tubular formation of HUVECs following inhibition of activin A by follistatin or shRNA, as well as by treatment of HUVECs with conditioned medium from activin A-depleted OSCC cells. Activin A-knockdown increased the migration of HUVECs. In addition, activin A stimulated the phosphorylation of SMAD2/3 and the expression and production of total VEGFA, significantly enhancing the expression of its pro-angiogenic isoform 121. The present findings suggest that activin $\mathrm{A}$ is a predictor of the prognosis of patients with OSCC, and provide evidence that activin $\mathrm{A}$, in an autocrine and paracrine manner, may contribute to OSCC angiogenesis through differential expression of the isoform 121 of VEGFA.

\section{Introduction}

Activin $\mathrm{A}$ is a member of the transforming growth factor- $\beta$ superfamily, which elicits pleiotropic effects in various 
biological systems, such as morphogenesis, organogenesis, growth, differentiation and regulation of reproduction $(1,2)$. Activin A signaling involves binding to type II transmembrane serine-threonine kinase receptors (ActRIIA or ActRIIB), which leads to the recruitment, phosphorylation and activation of type I activin receptors (ActRIA or ActRIB) $(3,4)$. The downstream signal transduction of activin A occurs via SMAD2/3, which form a complex with SMAD4 and translocate to the nucleus leading to transcription of target genes (4). The effects of activin A have also been associated with non-canonical pathways, including AKT/PI3K, MAPK/ERK and $\mathrm{WNT} / \beta$-catenin pathways $(4,5)$.

The effects of activin A are context-dependent and its dysregulation is associated with the development and progression of certain cancer types, including colorectal, prostate, lung and breast cancer (6-9). More than a basic marker of cancer progression, activin A also appears to influence survival by contributing to the development of cachexia and loss of skeletal muscle mass $(8,9)$. In previous studies, it was demonstrated that both oral squamous cell carcinoma (OSCC) cells and OSCC-associated fibroblasts express high levels of activin $\mathrm{A}$, which in an autocrine and paracrine manner, respectively, regulate apoptosis, proliferation and invasiveness of the tumor cells $(10,11)$. Furthermore, overexpression of activin A is clinically associated with lymph node metastasis, tumor differentiation and poor survival of patients with OSCC (11), and immunoexpression of activin $\mathrm{A}$ is a useful predictor of occult lymph node metastasis in patients with OSCC of the tongue (12). Tumor growth and metastasis depend on angiogenesis triggered by secreted factors from tumor and cells of the tumor microenvironment. The effects of activin A on angiogenesis remain controversial, with studies describing pro-angiogenic actions and associating its expression with poor prognosis of several cancer types, such as liver and breast cancer (13-15); however, other reports are contradictory (16-18). Increased production of activin A by hepatocellular and breast cancer cells that are no longer growth inhibited by activin A leads to increased angiogenesis by inducing vascular endothelial growth factor (VEGF) expression $(14,15)$. Nonetheless, to the best of our knowledge, whether activin A regulates angiogenesis in oral cancer remains unknown.

The present study investigated the prognostic significance of activin A immunoexpression in both blood vessels and tumor cells in a number of OSCC cases, and evaluated the impact of activin A on angiogenesis in vitro by assessing endothelial cell proliferation, migration and tube formation. Furthermore, to decipher its effects on angiogenesis, cDNA generated from activin A-treated human umbilical vein endothelial cells (HUVECs) and HUVECs stably expressing short hairpin RNA (shRNA) targeting activin A were subjected to a human angiogenesis quantitative PCR (qPCR) array, revealing enhanced amounts of total VEGFA and of its pro-angiogenic isoform 121. Collectively, the present study demonstrated that the assessment of activin A has a reliable prognostic value in OSCC, which may be, in part, due to the pro-angiogenic effects of activin A via stimulation of VEGFA production.

\section{Materials and methods}

Immunohistochemistry. To investigate the expression of activin A in blood vessels and in tumor cells, immunohistochemical analyses with anti-activin A and anti-CD34 antibodies were performed with 95 cases of primary OSCC from The Oncology Center of Cascavel (Paraná, Brazil) and The UOPECCAN Cancer Hospital (Paraná, Brazil), which were previously described (19). The samples were obtained between December 2012 and October 2013. The age range of the patients was 31-84 years, with a median of 56 years. OSCC consecutive slices from paraffin-embedded samples were subjected to immunostaining for activin A and CD34. Briefly, after dewaxing in xylene for 30 min and hydration in graded alcohol solutions $(100,90,80,70$, 60 and $50 \% ; 2 \mathrm{~min} / \mathrm{wash}$ ), the $3-\mu \mathrm{m}$ sections were treated with $3 \%$ hydrogen peroxide followed by antigen retrieval with $10 \mathrm{mM}$ citrate buffer $\mathrm{pH} 6.0$ in a pressure cooker for $15 \mathrm{~min}$. Following washing with PBS, the sections were treated with $1 \%$ bovine serum albumin in PBS at room temperature for $1 \mathrm{~h}$ and then incubated overnight at $4{ }^{\circ} \mathrm{C}$ with polyclonal rabbit activin $\mathrm{A}$ antibody (cat. no. HPA020031; 1:100; Sigma Aldrich-Aldrich) or monoclonal mouse CD34 antibody (cat. no. M7165; 1:400, clone QBEnd-10, Dako; Agilent Technologies, Inc.) at room temperature for $1 \mathrm{~h}$ followed by LSAB kit (LSAB+ system-HRP kit; Dako; Agilent Technologies, Inc.) or Advance HRP kit (Dako; Agilent Technologies, Inc.), respectively. Reactions were developed by incubating the sections with $0.6 \mathrm{mg} / \mathrm{ml} 3,3$ '-diaminobenzidine tetrahydrochloride (Dako; Agilent Technologies, Inc.) and counterstained with hematoxylin at room temperature for $2 \mathrm{~min}$. Control reactions were performed by omission of the primary antibodies.

Activin A immunoexpression was assessed in blood vessels and tumor cells by two independent pathologists, who were not aware of any clinical data. Activin A expression in blood vessels was determined by counting of activin A-positive and activin A-negative blood vessels in three magnification, x200 fields per sample with a light microscope, and samples were categorized into two groups based on median expression: Low ( $\leq 53 \%$ of activin A-positive blood vessels) and high ( $>53 \%$ of activin A-positive blood vessels). For tumor cells, the number of positive cells was graded according to the following: 1, $1-25 \%$ staining; $2,26-50 \%$ staining; $3,51-75 \%$ staining; and 4, $76-100 \%$ staining); and the intensity of staining was scored as follows: 0 , negative; 1 , weak staining; 2 , moderate staining; and 3, strong staining. The two grades were added together, producing scores from 0 to 7 that were classified as low (scores 0-4) and high (scores 5-7) expression for comparative analysis. Written informed consent was obtained from each patient according to the declaration of Helsinki, and the study was approved by the Human Research Ethics Committee of the School of Dentistry, University of Campinas (approval no. 100/2012, October 10, 2012).

Cell culture. HUVECs were obtained from American Type Culture Collection and cultured as recommended in a 1:1 mixture of Dulbecco's modified Eagle's medium and Ham's F12 medium (DMEM/F12; Invitrogen; Thermo Fisher Scientific, Inc.) supplemented with $10 \%$ fetal bovine serum (FBS; Cultilab), 400 ng/ml hydrocortisone (Sigma-Aldrich; Merck KGaA) and antibiotic-antimycotic (penicillin, streptomycin and amphotericin B solution; Thermo Fisher Scientific, Inc.). The SCC-9 ZsGreen LN-1 cells, isolated from a metastatic cervical lymph node (20), were cultured in DMEM/F-12 (Invitrogen; Thermo Fisher Scientific, Inc.) supplemented 
with 10\% FBS, 400 ng/ml hydrocortisone (Sigma-Aldrich; Merck KGaA) and antibiotic-antimycotic. shINHBA OSCC cells (SCC-9 ZsGreen LN-1 cells constitutively expressing a shRNA sequence against activin A) and the respective control (shControl OSCC cells; cells stably transfected with the same vector encoding a non-targeting scrambled shRNA sequence) were generated as previously described (11). All cells were cultured at $37^{\circ} \mathrm{C}$ in a humidified atmosphere of $5 \% \mathrm{CO}_{2}$.

Treatments. Lyophilized recombinant activin A (Sigma-Aldrich; Merck KGaA) and follistatin (R\&D Systems, Inc.) were dissolved in culture medium, aliquoted and stored at $-80^{\circ} \mathrm{C}$. To assess the effect of activin A, cells were cultured in DMEM/F-12 containing 0 or $1 \mathrm{ng} / \mathrm{ml}$ of recombinant activin A for $24 \mathrm{~h}$ at $37^{\circ} \mathrm{C}$. For follistatin treatment, cells were cultured at $100 \mathrm{ng} / \mathrm{ml}$ for $24 \mathrm{~h}$ at $37^{\circ} \mathrm{C}$. Concentrations of activin A and follistatin were selected based on our previous study (11).

Activin A stable knockdown in HUVECs. HUVECs grown in 12-well plates at a confluence of $50 \%$ were incubated with control shRNA lentiviral particles (MISSION ${ }^{\circledR}$ pLKO.1-puro Non-Mammalian shRNA Control; Sigma-Aldrich; Merck $\mathrm{KGaA}$ ) or INHBA shRNA lentiviral particles (INHBA MISSION $^{\circledR}$ shRNA Lentiviral Transduction Particles, NM_002192; 5'A-GACCCATGTCCATGTTGT-3'; Sigma-Aldrich; Merck KGaA) at a multiplicity of infection of 1.5 in culture medium containing $8 \mu \mathrm{g} / \mathrm{ml}$ polybrene (Sigma-Aldrich; Merck KGaA) for $8 \mathrm{~h}$. After washing with PBS, cells were cultured in fresh medium for an additional period of $48 \mathrm{~h}$. Cells were then split in a 1:5 dilution, and cultured for 10 days in the presence of $1 \mu \mathrm{g} / \mathrm{ml}$ puromycin dihydrochloride (Sigma-Aldrich; Merck KGaA) to select resistant cells. The efficacy of activin A-knockdown was determined by reverse transcription-qPCR (RT-qPCR) and enzyme-linked immunosorbent assay (ELISA).

$R T$ - $q P C R$. Total RNA was extracted using the RNeasy mini kit (Qiagen, Inc.), according to the manufacturer's protocol. Following DNase I treatment in order to eliminate genomic DNA contamination, $1 \mu \mathrm{g}$ total RNA per sample was used to generate cDNA using Oligo-dT (Invitrogen; Thermo Fisher Scientific, Inc.) and reverse transcriptase (Superscript II RT enzyme; Invitrogen; Thermo Fisher Scientific, Inc.), according to the manufacturer's protocol. The resulting cDNAs were subjected to qPCR using specific primers and SYBR Green PCR master mix (Applied Biosystems; Thermo Fisher Scientific, Inc.) in a Real Time PCR thermal cycler (Applied Biosystems; Thermo Fisher Scientific, Inc.). The thermocycling conditions were: $95^{\circ} \mathrm{C}$ for $1 \mathrm{~min}$ followed by 40 cycles $95^{\circ} \mathrm{C}$ for $15 \mathrm{sec}$ and $60^{\circ} \mathrm{C}$ for $30 \mathrm{sec}$. Gene expression was determined using the $2^{-\Delta \Delta \mathrm{Cq}}$ method (21) and PPIA was used as reference gene for data normalization. All reactions were performed in triplicate. Primer sequences are provided in Table SI.

ELISA. HUVECs were plated at concentration of 25,000 cells per well in a $24-w e l l$ culture plate in triplicate and cultured for $24 \mathrm{~h}$. After washing, the cells were cultured in serum-free medium for an additional $24 \mathrm{~h}$. The medium was then collected, centrifuged to remove floating cells, and used for analysis. The concentration of activin A was determined using a human activin A ELISA kit (cat. no. RAB0324; Sigma-Aldrich; Merck KGaA), according to the manufacturer's instructions.

Endothelial cell tube formation assay. HUVECs (40,000 cells per well) were seeded into wells of a 96-well plate coated with $50 \mu \mathrm{l}$ Matrigel (BD Biosciences). After $12 \mathrm{~h}$ of incubation, tube formation was observed under an inverted microscope (magnification, x40; Nikon Corporation), photographed and analyzed using Motic Images Plus 2.0 (Nikon Corporation), as previously described (22).

Proliferation analysis. HUVECs were plated in 96-well plates at a density of 10,000 cells per well in $100 \mu \mathrm{l}$ medium containing $10 \%$ FBS. After $16 \mathrm{~h}$, the cells were washed with PBS and cultured in serum-free medium for an additional $24 \mathrm{~h}$ to reach cell cycle synchronism. Following serum starvation, cells were treated for $24 \mathrm{~h}$ and proliferation rates were determined by measuring bromodeoxyuridine (BrdU) incorporation into DNA using a cell proliferation ELISA, BrdU (colorimetric) kit (cat. no. 11647229001; Roche Applied Science; Merck KGaA).

Migration analysis. Transwell migration assays were performed in $6.5-\mathrm{mm}$ inserts with $8-\mu \mathrm{m}$ pore size (Corning, Inc.). Serum-starved cells $(80,000$ cells/well) were plated into the upper chamber in $200 \mu \mathrm{l}$ serum-free DMEM/F12. As a chemoattractant in the lower chamber, depending on the assay, serum-free medium containing activin A or follistatin, and shINHBA OSCC- and shControl OSCC-conditioned medium were tested. Activin A or follistatin were also added in the upper chamber, in direct contact with the HUVEC cells, and in those situations $10 \%$ FBS was used in the lower chamber as chemoattractant. After $24 \mathrm{~h}$, assessment of migration was performed by gently removing cells in the interior part of the insert with a cotton swab. Cells on the underside of the membrane were fixed in $10 \%$ formalin for $15 \mathrm{~min}$ and stained with $1 \%$ toluidine blue in $1 \%$ borax solution, with both procedures at room temperature. The excess dye was washed out and cells were then eluted in $1 \%$ SDS solution for $5 \mathrm{~min}$. Absorbance was measured at $650 \mathrm{~nm}$.

qPCR array. To analyze the expression of pro- and anti-angiogenic factors, RNA from HUVEC cells treated with $1 \mathrm{ng} / \mathrm{ml}$ of activin A for $24 \mathrm{~h}$, alongside untreated controls, and from shControl-HUVECs and shINHBA-HUVECs were subjected to a human angiogenesis cDNA-based qPCR array (TaqMan ${ }^{\circledR}$ Array Human Angiogenesis; Applied Biosystems; Thermo Fisher Scientific, Inc.), according to the manufacturer's instructions.

Quantification of total VEGFA and isoforms. HUVECs were cultured in the presence of $1 \mathrm{ng} / \mathrm{ml}$ activin A for $24 \mathrm{~h}$ at $37^{\circ} \mathrm{C}$ and the expression of total VEGFA and of isoforms 121, 165 and 189 were evaluated by RT-qPCR. To assess the effects of activin $A$ on the production and secretion of total VEGFA and VEGFA isoform 121, ELISA was used. The concentration of VEGFA was determined using the human VEGFA ELISA kit (cat. no. RAB0507; Sigma-Aldrich; Merck KGaA) and the isoform 121 was evaluated with the human VEGFA isoform 121 ELISA kit (cat. no. SEB851Hu; Cloud-Clone Corp.), according to the manufacturers' instructions. 

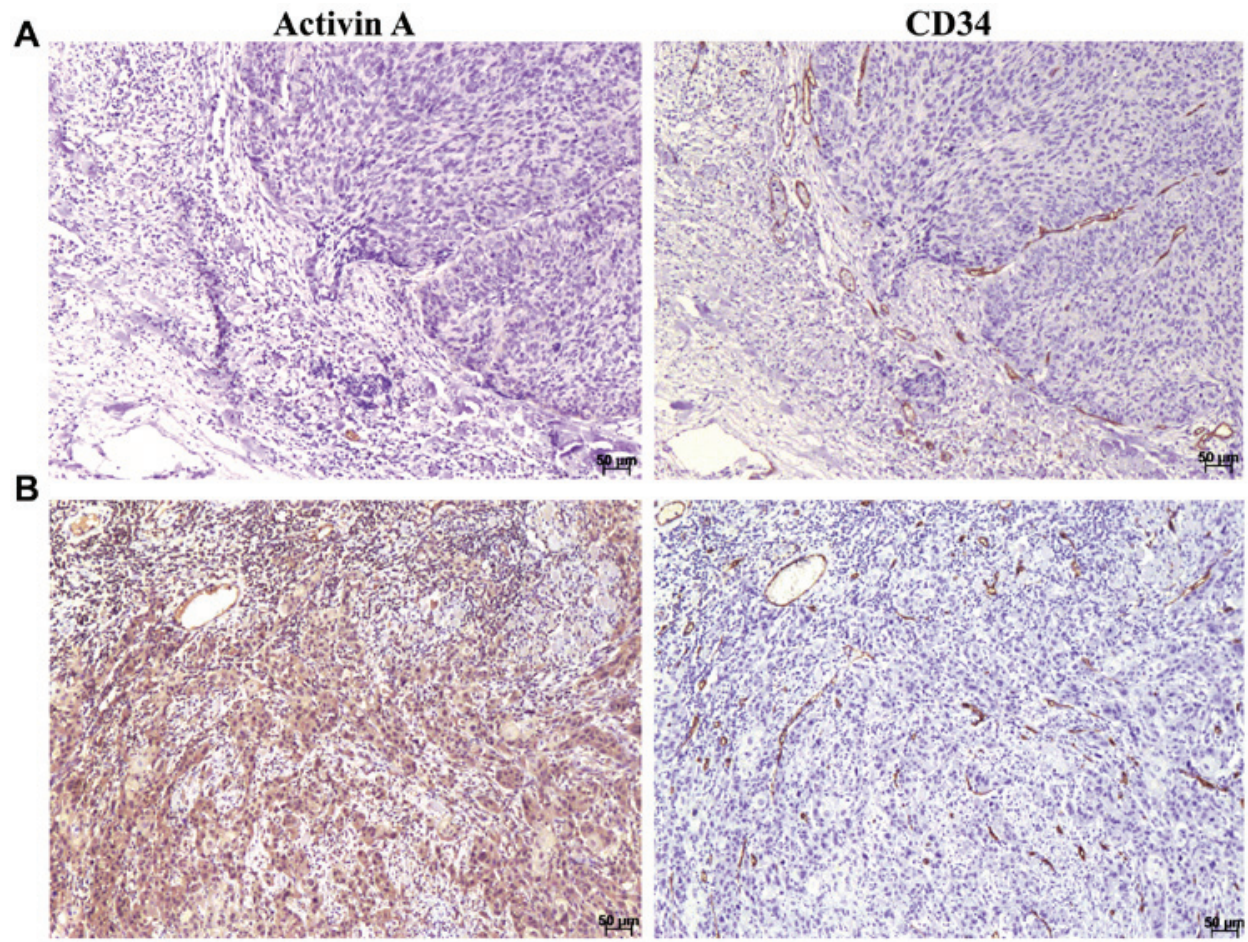

Figure 1. Activin A and CD34 immunohistochemical staining in consecutive slices of oral squamous cell carcinoma samples. (A) Representative samples classified as negative/low expression of activin A in both blood vessels and tumor cells. Positivity of CD34 aided in the identification of the blood vessels. (B) Representative samples with high activin A expression in both endothelial cells (blood vessels) and tumor cells.

Western blotting. Western blot analysis was used to determine the abundance of phosphorylated SMAD2/3. Cells were washed with cold PBS and lysed in cell lysis buffer (Cell Signaling Technology, Inc.) containing protease and phosphatase inhibitors. Following centrifugation, protein concentration was measured using a Bio-Rad Protein assay (Bio-Rad Laboratories, Inc.) according to the manufacturer's instructions. Total protein (30 $\mu \mathrm{g}$ per sample) was resolved by $10 \%$ SDS-PAGE under reducing conditions, and transferred to nitrocellulose membranes. The membranes were blocked with $10 \%$ non-fat dry milk in PBS containing 0.1\% Tween-20 at room temperature for $2 \mathrm{~h}$, rinsed in the same buffer, and incubated at room temperature for $2 \mathrm{~h}$ with the following primary antibodies: Polyclonal rabbit anti-phosphorylated SMAD2/3 (1:1,000; cat. no. 8828; Cell Signaling Technology, Inc.), polyclonal rabbit anti-SMAD2/3 (1:1,000; cat. no. 3102; Cell Signaling Technology, Inc.) and monoclonal rabbit anti-GAPDH (1:1,000; cat. no. 2118; Cell Signaling Technology, Inc.). Following washing, the membranes were incubated at room temperature for $1 \mathrm{~h}$ with polyclonal goat anti-rabbit IgG HRP-linked antibody (1:2,000; cat. no. 7074; Cell Signaling Technology, Inc.). Bands were detected using enhanced chemiluminescence western blotting system (GE Healthcare) and signals captured with an Alliance 9.7 instrument (UVITEC, Ltd.).

Statistical analysis. Associations between immunohistochemical expression of activin A in blood vessels and in tumor cells and clinicopathological parameters of the tumors were analyzed using a $\chi^{2}$ test. Survival curves were constructed based on the Kaplan-Meier method and compared with the log-rank test. For multivariate survival analysis, the Cox proportional hazard model with a stepwise method including all parameters was employed. Disease-specific survival (DSS) time was the time from treatment initiation until death due to cancer or the last known date alive, and disease-free survival (DFS) was the time from treatment initiation until diagnosis of the first recurrence (local, regional or distant) or the date of last follow up information for those without recurrence. Spearman's correlation test was applied for determine the correlation between activin A expression in blood vessels and in tumor cells.

All in vitro assays were performed at least three times in triplicate, and the results are presented as the mean \pm standard deviation. Differences were compared using Mann-Whitney's $\mathrm{U}$ test or one-way analysis of variance with post-hoc comparisons based on Tukey's multiple comparison test. All statistical analyses were performed using GraphPad Prism v6.01 (GraphPad Software, Inc.). P<0.05 was considered to indicate a statistically significant difference.

\section{Results}

Expression of activin A in blood vessels and tumor cells is associated with shortened survival time. To investigate whether activin A expression is associated with clinicopathological features of patients with OSCC, immunohistochemistry was performed in 95 cases of human OSCC. To quantify activin A abundance in blood vessels, immunohistochemistry for anti-CD34, a classical blood vessel marker, was performed concurrent with anti-activin A in serial sections (Fig. 1). Activin A was observed as a cytoplasmic stain with variable distribution and intensity in the endothelial cells of the blood vessels and in the tumor cells (Fig. 1). Expression was also observed in some inflammatory cells and cancer-associated fibroblasts. A significant correlation between activin A 
Table I. Association of the clinicopathological parameters of the oral squamous cell carcinoma cases with the immunohistochemical expression of activin A in blood vessels and tumor cells.

\begin{tabular}{|c|c|c|c|c|c|c|}
\hline \multirow[b]{2}{*}{ Parameter } & \multicolumn{3}{|c|}{ Activin A in blood vessels } & \multicolumn{3}{|c|}{ Activin A in tumor cells } \\
\hline & $\begin{array}{c}\text { Low expression, } \\
\mathrm{n}(\%)\end{array}$ & $\begin{array}{c}\text { High expression, } \\
\mathrm{n}(\%)\end{array}$ & P-value & $\begin{array}{l}\text { Low expression, } \\
\mathrm{n}(\%)\end{array}$ & $\begin{array}{c}\text { High expression, } \\
\text { n }(\%)\end{array}$ & $\mathrm{P}$-value \\
\hline \multicolumn{7}{|l|}{ Age, years } \\
\hline$<56$ & $25(55.6)$ & $23(46.0)$ & & $27(58.7)$ & $21(42.9)$ & \\
\hline$\geq 56$ & $20(44.4)$ & $27(54.0)$ & 0.35 & $19(41.3)$ & $28(57.1)$ & 0.12 \\
\hline \multicolumn{7}{|l|}{ Sex } \\
\hline Male & $39(86.7)$ & $42(84.0)$ & & $40(87)$ & $41(83.7)$ & \\
\hline Female & $6(13.3)$ & $8(16.0)$ & 0.71 & $6(13)$ & $8(16.8)$ & 0.65 \\
\hline \multicolumn{7}{|l|}{ Clinical stage } \\
\hline Early (I + II) & $22(48.9)$ & $22(44.0)$ & & $21(45.7)$ & $23(46.9)$ & \\
\hline Advanced (III + IV) & $23(51.1)$ & $28(56.0)$ & 0.63 & $25(54.3)$ & $26(53.1)$ & 0.90 \\
\hline \multicolumn{7}{|l|}{ Tumor site } \\
\hline Tongue & $26(57.8)$ & $21(42.0)$ & & $25(54.3)$ & $22(44.9)$ & \\
\hline Others & $19(42.2)$ & $29(58.0)$ & 0.12 & $21(45.7)$ & $27(55.1)$ & 0.36 \\
\hline \multicolumn{7}{|l|}{ Treatment } \\
\hline Surgery & $18(40.0)$ & $18(36.0)$ & & $20(43.5)$ & $16(32.7)$ & \\
\hline Surgery + RTX & $25(55.6)$ & $24(48.0)$ & & $22(47.8)$ & $27(55.1)$ & \\
\hline Surgery + RTX + CTX & $2(4.4)$ & $8(16.0)$ & 0.18 & $4(8.7)$ & $6(12.2)$ & 0.53 \\
\hline \multicolumn{7}{|l|}{ Histological grade } \\
\hline WD/MD & $42(93.3)$ & $43(86.0)$ & & $42(91.3)$ & $43(87.8)$ & \\
\hline PD & $3(6.7)$ & $7(14.0)$ & 0.25 & $4(8.7)$ & $6(12.2)$ & 0.57 \\
\hline \multicolumn{7}{|l|}{ Margin status, $\mathrm{mm}^{\mathrm{a}}$} \\
\hline$\geq 5$ & $40(90.9)$ & $49(98.0)$ & & $40(88.9)$ & $49(100.0)$ & \\
\hline$<5$ & $4(9.1)$ & $1(2.0)$ & 0.13 & $5(11.1)$ & $0(0.0)$ & 0.02 \\
\hline
\end{tabular}

${ }^{a} \mathrm{n}=94$ due to missing data. RTX, radiotherapy; CTX, chemotherapy; WD, well-differentiated; MD, moderately-differentiated; PD, poorly-differentiated.

expression in endothelial cells and in tumor cells was detected $(\mathrm{r}=0.6 ; \mathrm{P}<0.0001$; data not shown). In order to categorize samples regarding age and expression level, the median values were applied to separate samples into two groups. As presented in Table I, no significant associations were observed between activin A expression in blood vessels and the clinicopathological features of patients with OSCC. However, a significant association was identified between activin $\mathrm{A}$ expression in tumor cells and margin status $(\mathrm{P}=0.02$; Table I).

Univariate survival analysis based on log-rank test revealed a significant association of DSS with clinical stage of the tumor $(\mathrm{P}=0.001)$, histological grade $(\mathrm{P}=0.003)$, activin $\mathrm{A}$ expression in blood vessels $(\mathrm{P}=0.0002)$ and activin $\mathrm{A}$ expression in tumor cells $(\mathrm{P}=0.01$; Table II). High expression of activin $\mathrm{A}$ in tumor cells was a significant marker of reduced DSS, with a 5-year survival of $30 \%$ for the patients with high activin A expression compared with $56.3 \%$ for those with low activin A expression $(\mathrm{P}=0.01$; Fig. $2 \mathrm{C})$. For activin A expression in the blood vessels, the reduction in DSS was even more significant, with a 5-year survival of $24.8 \%$ for patients with high activin $\mathrm{A}$ expression compared with $63.8 \%$ for those with low activin A expression (Fig. 2A). DFS revealed a significant association with activin $\mathrm{A}$ expression in blood vessels ( $\mathrm{P}=0.03$; Table II), but not in tumor cells (Fig. 2D; Table II). The expression of activin $\mathrm{A}$ in the blood vessels was associated with a 5-year DFS of $43.1 \%$ for patients with high expression compared with $65.7 \%$ for patients with low expression (Fig. 2B). Multivariate Cox regression analysis confirmed that clinical stage [hazard ratio (HR), 2.02; 95\% confidence interval (CI), 1.09-3.73; $\mathrm{P}=0.03$ ), activin A expression in blood vessels (HR, 2.47; 95\% CI, 1.30-4.71; $\mathrm{P}=0.006)$ and activin $\mathrm{A}$ expression in tumor cells (HR, 1.63; 95\% CI, 1.08-2.45; $\mathrm{P}=0.02$ ) are independent risk factors for DSS of patients with OSCC (Table III). Furthermore, high expression of activin A in the blood vessels was determined to be an independent indicator of DFS (HR, 2.09; 95\% CI, 1.07-4.08; P=0.03; Table III).

In order to strengthen the prognostic information provided by these independent factors, activin A expression levels in blood vessels and in tumor cells were combined and analyzed for both univariate and multivariate survival. Combination of clinical stage with activin A expression in blood vessels and with activin A expression in the tumor cells were also evaluated. In all combinations, the discriminatory ability to predict survival of patients with OSCC was largely improved 
Table II. Univariate analysis for disease-specific survival and disease-free survival of the oral squamous cell carcinoma patients.

\begin{tabular}{|c|c|c|c|c|c|c|}
\hline \multirow[b]{2}{*}{ Parameter } & \multicolumn{3}{|c|}{ Disease-specific survival rate } & \multicolumn{3}{|c|}{ Disease-free survival rate } \\
\hline & 5 years, $\%$ & HR (95\% CI) & P-value & 5 years, $\%$ & HR $(95 \%$ CI $)$ & P-value \\
\hline \multicolumn{7}{|l|}{ Age, years } \\
\hline$<56$ & 53.2 & 1 & & 55.8 & 1 & \\
\hline$\geq 56$ & 31.7 & $1.41(0.81-2.46)$ & 0.20 & 51.5 & $1.16(0.62-2.17)$ & 0.63 \\
\hline \multicolumn{7}{|l|}{ Sex } \\
\hline Male & 45.4 & 1 & & 55.9 & 1 & \\
\hline Female & 33.3 & $1.21(0.54-2.71)$ & 0.61 & 46.2 & $1.25(0.52-3.04)$ & 0.57 \\
\hline \multicolumn{7}{|l|}{ Clinical stage } \\
\hline Early (I + II) & 60.4 & 1 & & 62.1 & 1 & \\
\hline Advanced (III + IV) & 29.7 & $2.52(1.45-4.36)$ & 0.001 & 46.7 & $1.67(0.89-3.13)$ & 0.10 \\
\hline \multicolumn{7}{|l|}{ Tumor site } \\
\hline Tongue & 38.3 & 1 & & 52.9 & 1 & \\
\hline Others & 45.5 & $0.87(0.50-1.50)$ & 0.61 & 55.4 & $1.08(0.57-2.03)$ & 0.80 \\
\hline \multicolumn{7}{|l|}{ Treatment } \\
\hline Surgery & 55.1 & 1 & & 67.5 & 1 & \\
\hline Surgery + RTX & 33.5 & $1.47(0.82-2.66)$ & & 47.3 & $1.64(0.83-3.24)$ & \\
\hline Surgery + RTX + CTX & 33.3 & $1.22(0.50-2.94)$ & 0.43 & 50.0 & $1.59(0.51-4.65)$ & 0.38 \\
\hline \multicolumn{7}{|l|}{ Histological grade } \\
\hline WD/MD & 45.8 & 1 & & 55.5 & 1 & \\
\hline PD & 22.2 & $3.09(0.86-11.1)$ & 0.003 & 35.7 & $1.96(0.49-7.79)$ & 0.18 \\
\hline \multicolumn{7}{|l|}{ Margin status, mm } \\
\hline$\geq 5$ & 75.0 & 1 & & 75.0 & 1 & \\
\hline$<5$ & 42.4 & $2.64(0.75-9.30)$ & 0.31 & 53.6 & $2.16(0.53-8.69)$ & 0.43 \\
\hline \multicolumn{7}{|l|}{ Activin A in blood vessels } \\
\hline Low expression & 63.8 & 1 & & 65.7 & 1 & \\
\hline High expression & 24.8 & $2.86(1.65-4.97)$ & 0.0002 & 43.1 & $1.93(1.03-3.64)$ & 0.03 \\
\hline \multicolumn{7}{|l|}{ Activin A in tumor cells } \\
\hline Low expression & 56.3 & 1 & & 62.9 & 1 & \\
\hline High expression & 30.0 & $1.95(1.12-3.38)$ & 0.01 & 45.7 & $1.81(0.96-3.39)$ & 0.06 \\
\hline
\end{tabular}

RTX, radiotherapy; CTX, chemotherapy; WD, well-differentiated; MD, moderately-differentiated; PD, poorly-differentiated; HR, hazard ratio; $\mathrm{CI}$, confidence interval.

(Table IV). Activin A expression in tumor cells was not individually associated with DFS in either univariate or multivariate analysis, but when combined with activin A expression in the blood vessels and with clinical stage, a significant association was observed, revealing a prognostic discrimination. Collectively, these findings suggest that the expression levels of activin $\mathrm{A}$ in both blood vessels and tumor cells could be used as risk factor to predict poor prognosis of OSCC.

Activin A promotes tubulogenesis in HUVECs. Since tube morphogenesis is a critical step in the formation of blood vessels, the present study first assessed the importance of activin A for the tubulogenesis of HUVECs. Cells were treated with recombinant activin $\mathrm{A}$, the activin $\mathrm{A}$-antagonist follistatin or were transduced with lentivirus carrying shINHBA. shINHBA-transfected HUVECs demonstrated a significant reduction in both activin A
mRNA and protein levels in comparison with cells transfected with shControl (Fig. S1). A significant increase in the HUVEC tubulogenesis was observed in cells treated with $1 \mathrm{ng} / \mathrm{ml}$ activin A ( $\mathrm{P}<0.01$; Fig. 3A). Conversely, follistatin significantly reduced the tubulogenic activity of HUVECs ( $\mathrm{P}<0.01$; Fig. 3A). In addition, shINHBA-transfected HUVECs generated a significantly lower number of tubes compared with shControl-transfected HUVECs $(\mathrm{P}<0.05$; Fig. 3B). Similar inhibition was observed when HUVECs were cultured in the presence of conditioned medium harvested from shINHBA OSCC cells compared with shControl OSCC cells ( $\mathrm{P}<0.01$ : Fig. 3C).

Activin A effects the proliferation and migration of HUVECs. To improve understanding of the role of activin A in the events that control tubulogenesis, the effects of activin A on the proliferation and migration of HUVECs were evaluated. Compared 
Table III. Cox multivariate analysis for the risk of mortality.

Disease-specific survival

Disease-free survival

\begin{tabular}{|c|c|c|c|c|}
\hline \multirow[b]{2}{*}{ Parameter } & & \\
\hline & $\mathrm{HR}(95 \% \mathrm{CI})$ & P-value & $\mathrm{HR}(95 \% \mathrm{CI})$ & P-value \\
\hline \multicolumn{5}{|l|}{ Clinical stage } \\
\hline Early (I + II) & 1 & & & \\
\hline Advanced (III + IV) & $2.02(1.09-3.73)$ & 0.03 & & \\
\hline \multicolumn{5}{|c|}{ Activin A in blood vessels } \\
\hline Low expression & 1 & & 1 & \\
\hline High expression & $2.47(1.30-4.71)$ & 0.006 & $2.09(1.07-4.08)$ & 0.03 \\
\hline \multicolumn{5}{|c|}{ Activin A in tumor cells } \\
\hline Low expression & 1 & & & \\
\hline High expression & $1.63(1.08-2.45)$ & 0.02 & & \\
\hline
\end{tabular}

HR, hazard ratio; CI, confidence interval.

A

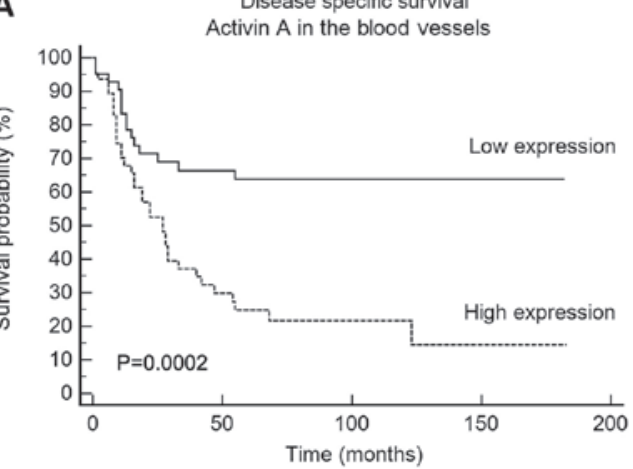

C

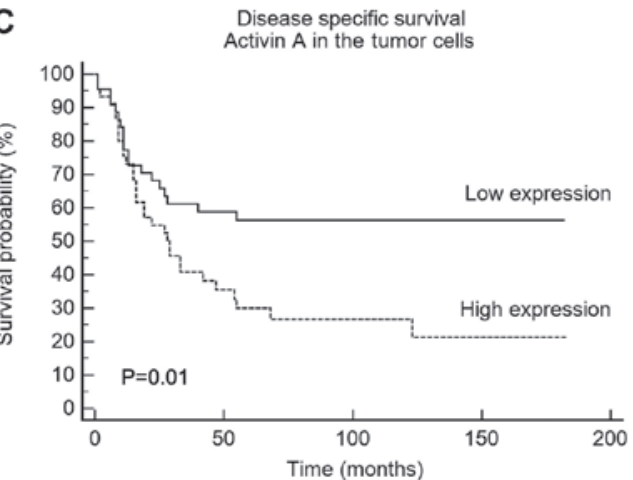

B

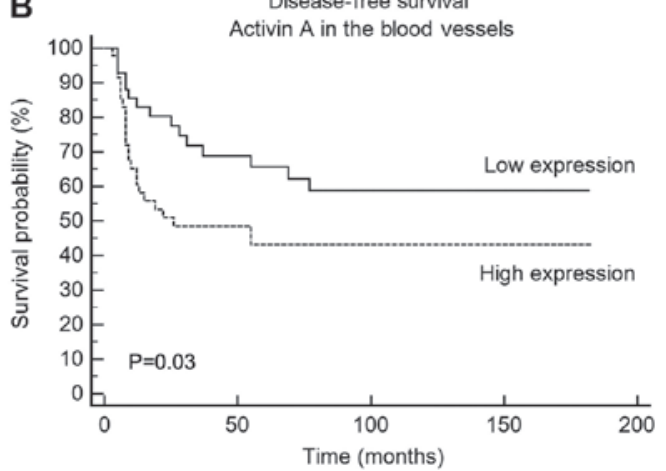

D

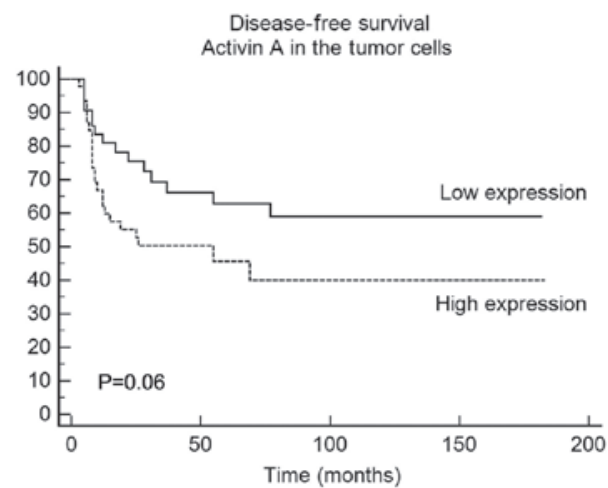

Figure 2. Kaplan-Meier cumulative curves for disease specific survival and disease-free survival. Patients with oral squamous cell carcinoma were divided in low and high expression groups based on the activin A levels in blood vessels and in tumor cells. Patients with high activin expression in blood vessels exhibited significantly reduced (A) DSS and (B) DFS. High expression of activin A in tumor cells was associated with a significantly reduced (C) DSS but not with (D) DFS. DSS, disease specific survival; DFS, disease free-survival.

with untreated cells, activin A significantly increased the proliferation of HUVECs $(\mathrm{P}<0.05$; Fig. 4A). Conversely, the proliferation of HUVECs was decreased, but not at significant level, after $24 \mathrm{~h}$ treatment with $100 \mathrm{ng} / \mathrm{ml}$ follistatin (Fig. 4A), and by gene silencing of activin $\mathrm{A}(\mathrm{P}<0.01$; Fig. 4B). Treatment of HUVECs with conditioned medium collected from shINHBA OSCC cells also significantly decreased HUVEC proliferation in comparison with conditioned medium from shControl OSCC cells ( $\mathrm{P}<0.05$; Fig. 4C).
The migration of HUVECs was not affected by activin A or follistatin directly in the upper chamber or when used as chemoattractant in the lower chamber of the Transwell system (Fig. 5A and B). However, activin A-knockdown significantly increased the migration of HUVEC cells $(\mathrm{P}<0.01$; Fig. 5C). When conditioned medium collected from shINHBA OSCC cells was used as a chemoattractant, a significant increase in migration of HUVECs was observed $(\mathrm{P}<0.01$; Fig. 5D). 
Activin A promotes differential expression of genes related to angiogenesis. To identify putative activin A-target genes, the expression of angiogenesis-related genes in HUVEC cells treated with activin A and in shINHBA-transfected HUVECs was profiled. Up- and downregulated genes were defined as those with an expression level $>2.0$ - or $<2.0$-fold different in an average of 3 independent experiments. Table SII presents the up- and downregulated genes in HUVECs treated with activin A compared with untreated HUVEC cells and in shINHBA-transfected cells compared with shControl-transfected cells. VEGFA was markedly upregulated by activin A treatment (29.6-fold), whereas it was downregulated in HUVEC shINHBA-transfected cells compared with shControl-transfected HUVECs (-3.0-fold).

Effects of activin $A$ on the expression of VEGFA and VEGFA isoforms. Considering that VEGFA was markedly regulated by activin A and given that VEGFA is the main regulator of angiogenesis $(13,14)$, RT-qPCR was performed to determine the effects of activin A on the expression of total VEGFA and its major isoforms. The results demonstrated that compared with the untreated control, activin A significantly increased the expression of total VEGFA $(\mathrm{P}<0.01)$ and the pro-angiogenic isoform VEGFA121 ( $\mathrm{P}<0.01$; Fig. 6A). A significant decrease of VEGFA165 was detected in cells treated with activin A $(\mathrm{P}<0.001$; Fig. 6A). Accordingly, significantly higher levels of total VEGFA $(\mathrm{P}<0.01)$ and VEGFA121 $(\mathrm{P}<0.05)$ were secreted by HUVECs following treatment with activin $\mathrm{A}$ in comparison with the control (Fig. 6B and C).

SMAD2/3 signaling is activated by activin A. Activin A signaling is mediated by the SMAD pathway and VEGFA is positively regulated by SMAD2/3 $(4,13,14)$. The present study therefore examined whether activin A stimulates SMAD2/3 phosphorylation in HUVECs. After 30 min of stimulation, increased phosphorylated SMAD2/3 levels were observed in HUVECs treated with $1 \mathrm{ng} / \mathrm{ml}$ activin A (Fig. 6D).

\section{Discussion}

Angiogenesis is an essential requirement for growth and progression of solid tumors; however, the underlying molecular mechanisms remain unclear (23). The present study confirmed that activin $\mathrm{A}$ has a relevant prognostic role for aggressive OSCC and this finding was supported by in vitro evidence of a pro-angiogenic role for activin A with both autocrine and paracrine (tumor-secreted) effects. Initially it was observed that the expression of activin A in blood vessels is a significant and independent risk factor to predict relapse and shortened survival of patients with OSCC. The present results also demonstrated that increased expression of activin A by tumor cells is strongly associated with poor prognosis of patients with OSCC, and the combination of activin A overexpression in both tumor cells and blood vessels improved the discrimination of patients at lowand high-risk of poor prognosis. Expression of activin A has previously been described in tumors cells and in components of the tumor microenvironment, including cancer-associated fibroblasts, blood vessels and some tumor-infiltrating inflammatory cells in OSCC $(10-12,24,25)$. The present study extends the reports of increased expression of activin A in neoplastic 
A

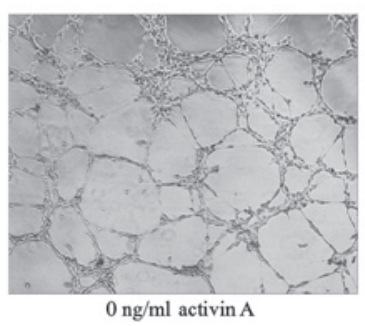

B

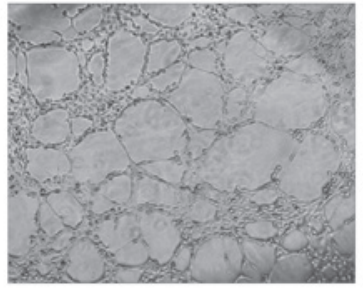

shControl HUVECs

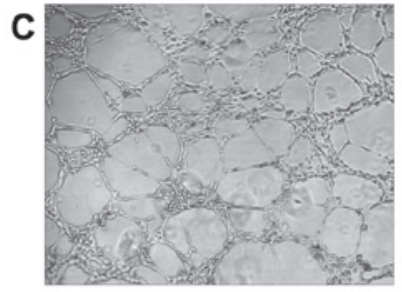

shControl OSCC cells

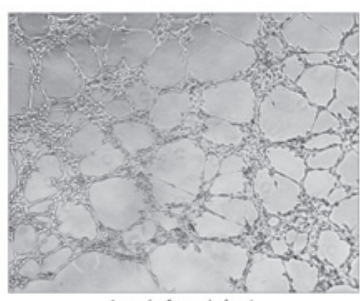

$1 \mathrm{ng} / \mathrm{ml}$ activin $\mathrm{A}$

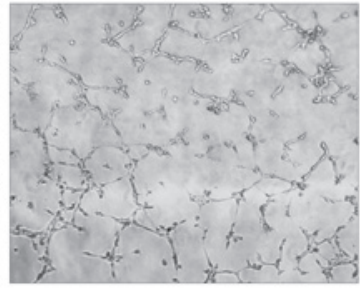

ShINHBA HUVECs

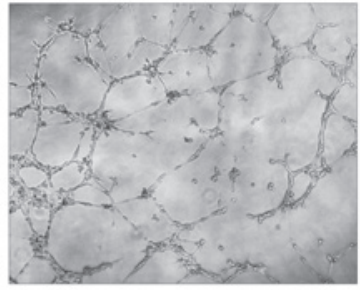

shINHBA OSCC cells
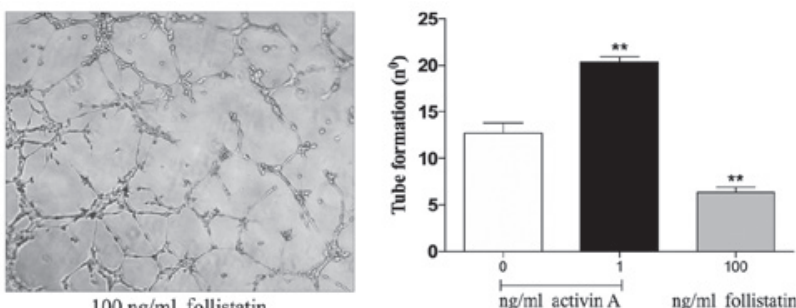

$100 \mathrm{ng} / \mathrm{ml}$ follistatin
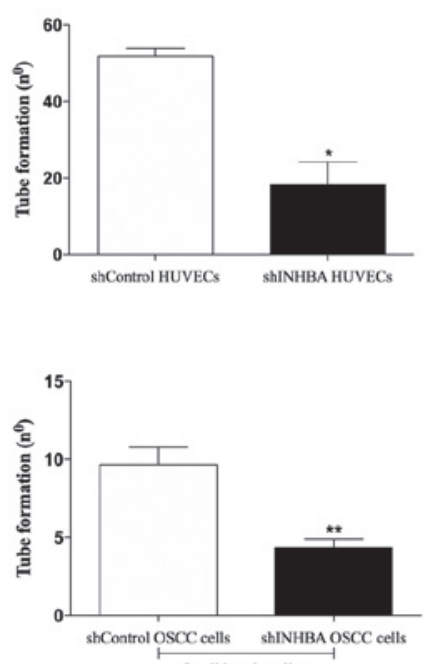

Confitioned medium

Figure 3. Activin A promotes tubulogenesis in vitro. HUVECs were seeded into 96 -well plates precoated with $50 \mu 1$ Matrigel and tube formation was quantified after $12 \mathrm{~h}$. (A) Representative images of the capillary-like structures of the control cells, cells treated with $1 \mathrm{ng} / \mathrm{ml}$ recombinant activin A and cells incubated with $100 \mathrm{ng} / \mathrm{ml}$ of follistatin. Treatment with activin A for $12 \mathrm{~h}$ significantly induced tube formation, whereas the number of structures was significantly inhibited by follistatin treatment. (B) Knockdown of activin A in HUVECs significantly inhibited tubulogenesis. (C) Treatment of HUVECs with conditioned medium harvested from OSCC cells with shRNA-mediated silencing of activin A significantly decreased tube formation in comparison with control (non-targeted) shRNA OSCC cells. Magnification, $\mathrm{x} 40 .{ }^{*} \mathrm{P}<0.05,{ }^{* * *} \mathrm{P}<0.01$ vs. untreated or shControl cells. HUVEC, human umbilical vein endothelial cell; shRNA, short hairpin RNA; OSCC, oral squamous cell carcinoma.
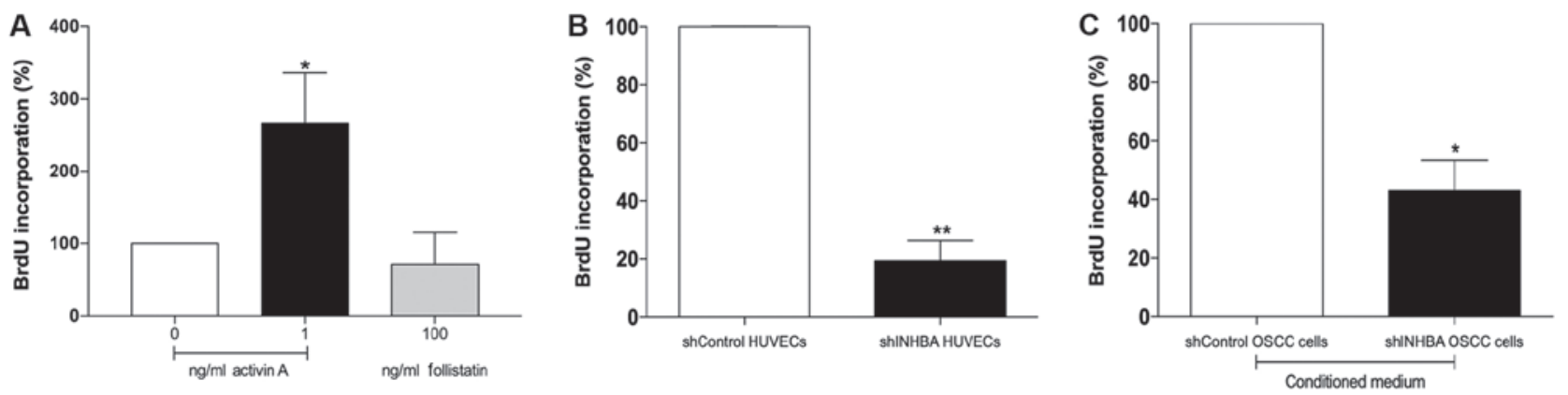

Figure 4. Activin A effects the proliferation of HUVECs. Proliferation rates were assessed by quantification of BrdU incorporation, and apoptotic cells were stained with annexin V-PE and propidium iodide and analyzed by flow cytometry. (A) Treatment with $1 \mathrm{ng} / \mathrm{ml}$ recombinant activin A for $24 \mathrm{~h}$ significantly induced the proliferation of HUVECs, but the treatment with activin A antagonist follistatin was not able to significantly alter the proliferation of HUVECs. (B) Knockdown of activin A significantly decreased BrdU incorporation in HUVECs. (C) Proliferation of HUVECs treated with conditioned medium of shINHBA OSCC cells was inhibited in comparison with proliferation of HUVECs treated with conditioned medium from shControl OSCC cells. "P<0.05, ${ }^{* *} \mathrm{P}<0.01$ vs. untreated or respective shControl cells. HUVEC, human umbilical vein endothelial cell; shRNA, short hairpin RNA; OSCC, oral squamous cell carcinoma; BrdU, bromodeoxyuridine.

and endothelial cells in OSCC and demonstrates a significant association with shortened survival. Besides the important role in the development of various types of cancer (6-9), previous studies have indicated that high levels of circulating activin $\mathrm{A}$ is an independent prognostic factor of survival in pancreatic, lung, breast and colorectal cancer (26-29), which may be associated with its contribution to the development of cachexia and loss of skeletal muscle mass (8). Altogether, activin A has an important role in the development and progression of numerous cancers, including OSCC.

The present study also revealed that activin A regulates essential cell biology aspects associated with angiogenesis, such as the proliferation, migration and tubulogenic activity of the endothelial cells. Pro-angiogenic effects were associated with stimulation of endothelial cells directly with activin A or with conditioned medium from OSCC cells expressing 

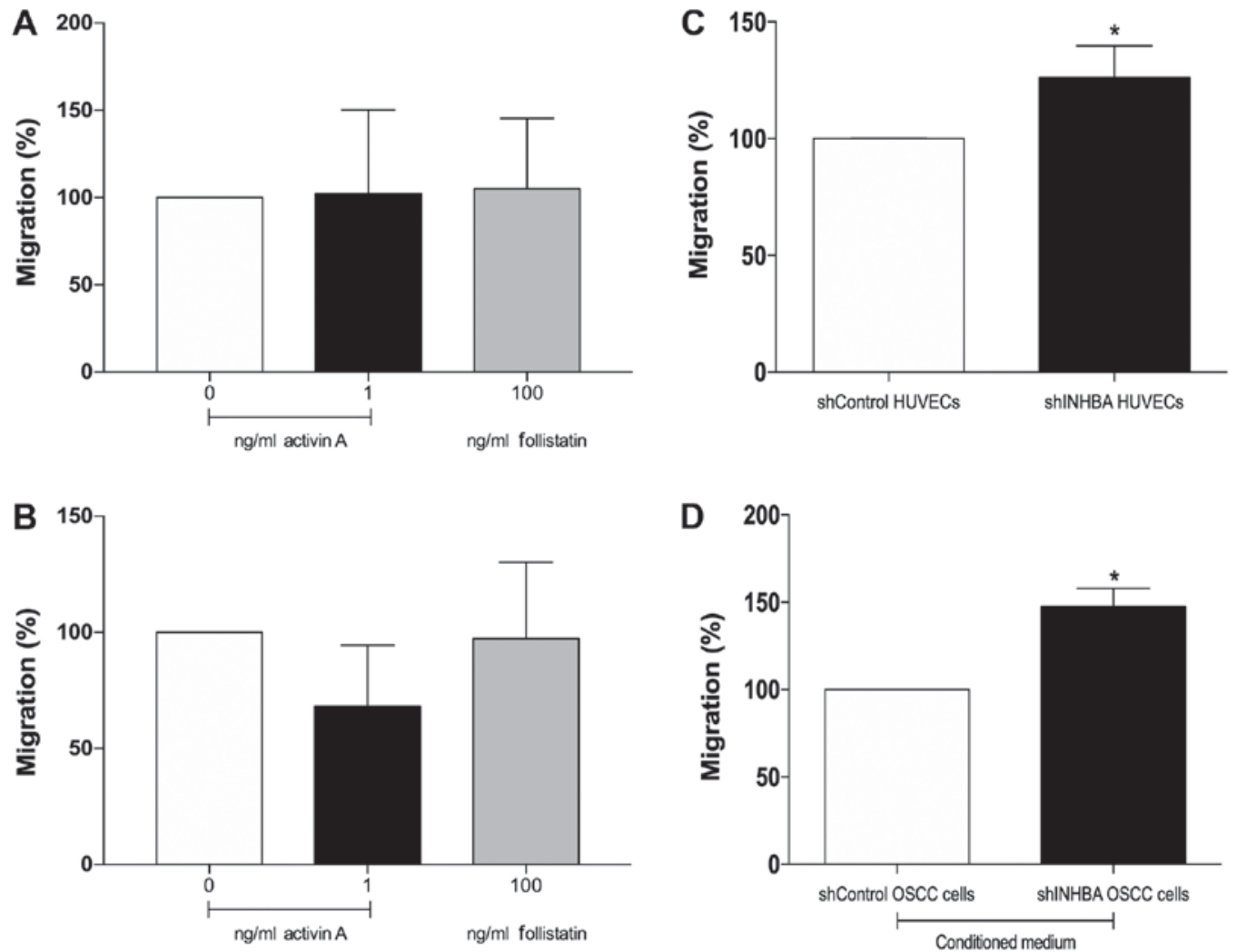

Figure 5. Downregulation of activin A induces migration of HUVECs. Activin A and follistatin added directly into the upper chamber (A) or when used as chemoattractants in the lower chamber of the Transwell system (B) were not able to modulate the migration of the HUVECs. (C) Knockdown of activin A significantly increased the migration of HUVECs. (D) Conditioned medium from shINHBA OSCC cells increased HUVEC migration significantly in comparison with conditioned medium from shControl OSCC cells. "P<0.01 vs. shControl cells. HUVEC, human umbilical vein endothelial cell; shRNA, short hairpin RNA; OSCC, oral squamous cell carcinoma.
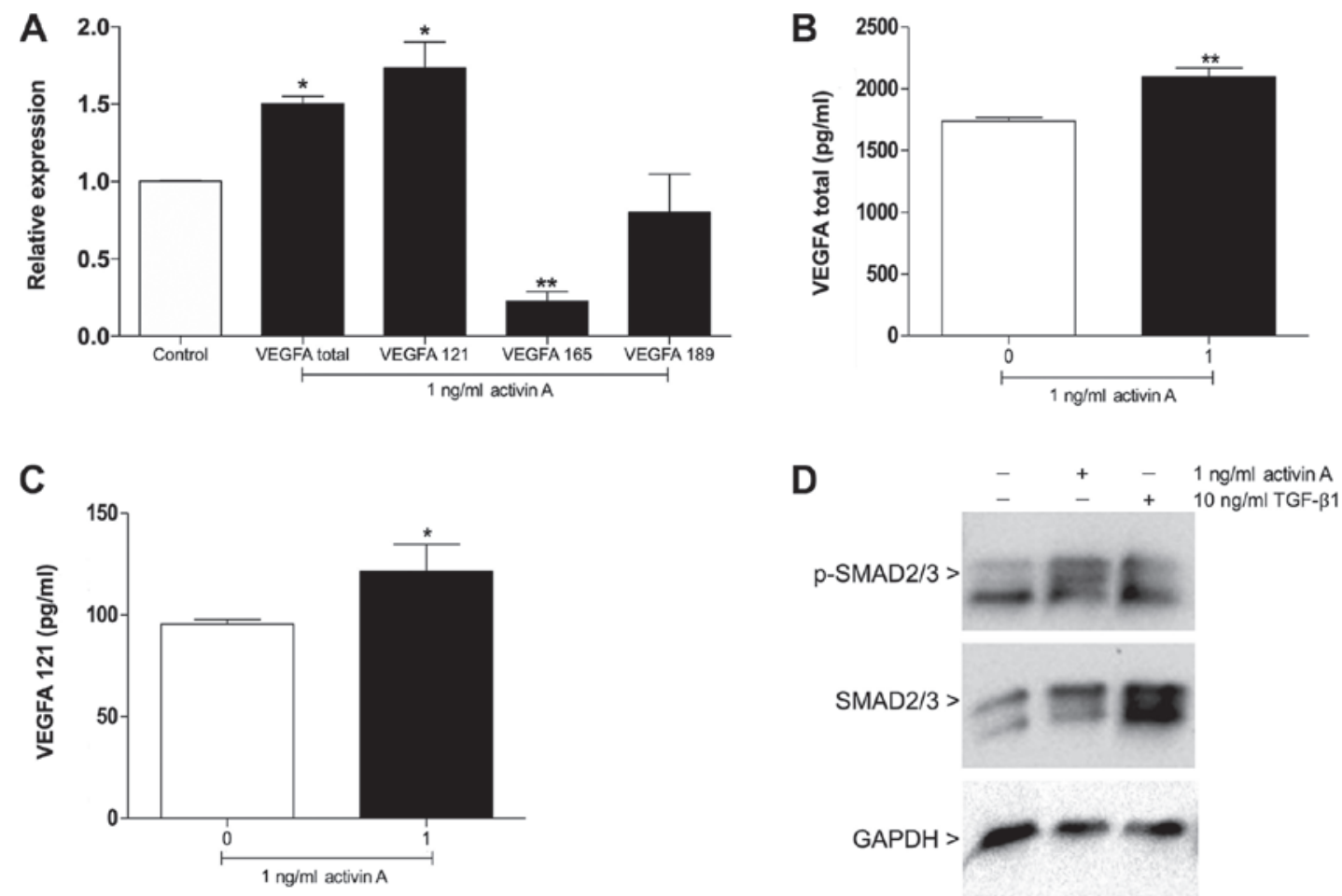

Figure 6. Activin A increases secretion of VEGFA and triggers phosphorylation of SMAD2/3. (A) Treatment with activin A significantly increased the expression of total VEGFA and of pro-angiogenic isoform 121, and downregulated VEGFA165. High levels of (B) total VEGFA and (C) VEGFA121 were also detected in culture supernatants from HUVECs treated with activin A by ELISA. (D) Western blotting of both p-SMAD2/3 and total SMAD2/3 after treatment of HUVECs with activin A. As a control, cells were treated with $10 \mathrm{ng} / \mathrm{ml}$ TGF- $\beta$. Treatment with activin A induced the phosphorylation of SMAD2/3. "P $<0.05$, ${ }^{* *} \mathrm{P}<0.01$ vs. untreated cells. VEGFA, vascular endothelial growth factor A; p-, phosphorylated; HUVEC, human umbilical vein endothelial cell. 
activin $\mathrm{A}$, and these effects were reversed when endogenous expression of activin A was inhibited in endothelial cells and when these cells were treated with an activin A inhibitor (follistatin) or with conditioned medium from tumor cells with shRNA-mediated knockdown of activin A. These findings agree with other reports reporting tubulogenic stimulation of activin A in vascular endothelial cells $(13,30)$ and with its association with breast and skin cancer development and progression in vivo $(3,15,31)$. In melanomas, paracrine activin A signaling stimulates tumor vascularization and promotes tumor growth and metastasis through mechanisms of immune evasion (32). However, some studies have demonstrated that activin A inhibits proliferation and suppresses tubulogenic activity of endothelial cells isolated from human umbilical veins of newborns, bovine adrenal or brain capillary and calf pulmonary artery, or in mice experimental neuroblastomas (16-18,33-35). The present results demonstrated that inhibition of activin A promotes migration of HUVEC cells. In a recent study, activin A neutralization promoted primary microvascular endothelial cell migration as well as essential steps in the expansion and formation of the vasculature (36). In prostate cancer, activin A enhances cell migration through increasing androgen receptor gene transcription, nuclear translocation and interaction with SMADs (37). The formation of capillary-like tubes in vitro on basement membrane matrix, as applied in the present study, represents the later stages of the angiogenic process in which the endothelial cells differentiate into tubes simulating the in vivo situation. This assay is dependent on a series of events, including the proliferation, migration and differentiation of the cells (38). Thus, expansion and migration of precursor cells prior to differentiation are essential for vessel formation.

It was speculated that activin A influences a network of other angiogenesis-related genes to promote angiogenesis and tumor growth. Supporting this hypothesis, the present study observed that activin A treatment induces the expression of several genes in the angiogenesis pathway, most of them favoring angiogenesis. Some these genes included the following: AMOT, which has been shown to promote vascular development in vivo by regulating motility of the endothelial cells (39); HSPG2, which promotes vascular formation and angiogenesis by modulating FGF2 activity (40); and FGF2, a critical mediator of capillary formation (30). Notably, activin A was revealed to modulate the expression of VEGFA. Expression of total VEFGA was significantly increased by treatment of HUVEC cells with recombinant activin $\mathrm{A}$, whereas silencing activin $\mathrm{A}$ gene expression significantly reduced expression of VEGFA. Treatment of endothelial cells with activin A activated SMAD2/3, suggesting that this signaling may be involved in the regulation of VEGFA by activin A in these cells. This is consistent with previous evidence that activin A predominantly mediates intracellular signaling via phosphorylation of SMADs, and the oligomer of SMAD2/3 and SMAD4 acts as a transcription regulator of various target genes $(4,41)$. In support of the present findings, activin A has been demonstrated to be critically relevant for VEGF-induced tubulogenesis, and the VEGF-induced pathway is almost completely inhibited when the secretion of activin A is blocked (13). The functional relevance of SMAD2 for activin A-induced VEGF expression is also supported by observations that SMAD2 overexpression significantly enhances VEGF levels in human hepatocellular carcinoma cells, and SMAD2 dominant negative mutant inhibits activin A responsiveness, abrogating VEGF stimulation (14). Notably, activin A expression is a predictive marker of response to treatment with the anti-VEGF antibody bevacizumab in metastatic melanoma (42). However, a lack of a specific assay connecting activin A, phosphorylation of SMADs and regulation of VEGFA in the context of angiogenesis is a limitation of the study that merits additional investigation.

VEGFA is considered a key mediator of angiogenesis and its expression has been implicated in tumor development and metastasis $(23,43)$. Due to alternative splicing, VEGFA gene is translated into a number of isoforms, with VEGFA121, VEGFA165 and VEGFA189 being the most prevalent in humans (44). In OSCC, increased expression of total VEGFA has been described as an independent prognostic indicator of reduced survival and increased recurrence (45). VEGFA isoforms 121, 165 and 189 are expressed at high levels in OSCC cells and increased expression of isoform 165 is associated with poorer prognosis (46). Assessing the main pro-angiogenic isoforms of VEGFA, the present study observed an enhanced expression and secretion of isoform 121 and a downregulation of isoform 165 in HUVECs stimulated with activin A. The balance in the expression of VEGFA isoforms produced by alternative splicing seems to be important for angiogenesis in physiological and pathological conditions (44). VEGFA121 lacks the heparin-binding motif and thus can diffuse relatively freely through the extracellular matrix, inducing malformed and leaky vessels (47). High concentrations of VEGFA121 also promote the development of vessels with enhanced diameter, whereas its lower concentration produces the growth of long and thin vessels (48). The abnormality of the tumor vasculature is already well documented in the literature, constituting not only an obstacle to the efficacy of the available chemotherapeutic agents but also providing a route for metastatic dissemination $(49,50)$. The high intratumoral vascular permeability associated with the absence of functional lymphatic vessels results in the elevation of interstitial pressure, which constitutes a physiological barrier to the delivery of chemotherapeutic agents inside the tumor. On the other hand, the blockage of blood and oxygen supplies creates a hypoxic and acidic microenvironment in the tumor, which fosters tumor cells to become more aggressive and metastatic $(50,51)$. However, current tumor antiangiogenic and vascular normalizing drugs display only moderate anticancer efficacy (50). Therefore, activin A blockade may be a promising therapeutic approach as it would inhibit the formation of new blood vessels, as well the development of a disorganized tumor vasculature by isoform 121 of VEGFA.

Activin A serves an important role in tumorigenesis, mostly acting by regulation of tumors cells but also by the regulating tumor microenvironment, such as cancer-associated fibroblast accumulation and angiogenesis. Collectively, the present findings expand the knowledge regarding the prognostic value of activin A expression in OSCC, and further suggest that activin A signaling promotes angiogenesis, at least in part, by inducing SMAD2/3 activation and the expression of VEGFA isoform 121. Although other studies are required to clarify the precise mechanisms by which activin A/SMAD/VEGFA121 signaling is implicated in angiogenesis, the clinical potential of activin A as a prognostic marker, a therapeutic target or a marker for post-therapeutic monitoring of locoregional recurrence should be considered in OSCC. 


\section{Acknowledgements}

The authors would like to thank Dr Fabio Haach Teo (University of Campinas, São Paulo, Brazil) for his excellent technical assistance.

\section{Funding}

This study was supported by grants from the São Paulo Research Foundation-FAPESP (grant nos. 2013/19856-2 and 2013/01607-6), and from the National Council for Scientific and Technological Development-CNPq, Brasília, Brazil (grant no. 302964/2015-0).

\section{Availability of data and materials}

All data generated or analyzed during this study are included in this published article.

\section{Authors' contributions}

CEO, CRJ, DL, TS, EG and RC conceived and designed the experiments. CEO, MRD, MCM, NKC and JEL performed the experiments. IS-C contributed with clinical samples, including the generation and analysis of clinical, pathological and survival data. CEO, MRD, CRJ, NKC and RC analyzed the data. $\mathrm{CEO}$ and $\mathrm{RC}$ wrote the manuscript. All authors read and approved the final manuscript.

\section{Ethics approval and consent to participate}

Written informed consent was obtained from each patient according to the declaration of Helsinki, and the study was approved by the Human Research Ethics Committee of the School of Dentistry, University of Campinas (approval no. 100/2012, Oct 10th, 2012).

\section{Patient consent for publication}

Not applicable.

\section{Competing interests}

The authors declare that they have no competing interests.

\section{References}

1. Matzuk MM, Kumar TR, Vassalli A, Bickenbach JR, Roop DR, Jaenisch R and Bradley A: Functional analysis of activins during mammalian development. Nature 374: 354-356, 1995.

2. Ying SY, Zhang Z, Furst B, Batres Y, Huang G and Li G: Activins and activin receptors in cell growth. Proc Soc Exp Biol Med 214: $114-122,1997$.

3. Antsiferova M and Werner S: The bright and the dark sides of activin in wound healing and cancer. J Cell Sci 125: 3929-3937, 2012.

4. Loomans HA and Andl CD: Intertwining of Activin A and TGF $\beta$ Signaling: Dual roles in cancer progression and cancer cell invasion. Cancers (Basel) 7: 70-91, 2014.

5. McDowell N, Zorn AM, Crease DJ and Gurdon JB: Activin has direct long-range signalling activity and can form a concentration gradient by diffusion. Curr Biol 7: 671-681, 1997.

6. Wildi S, Kleeff J, Maruyama H, Maurer CA, Büchler MW and Korc M: Overexpression of activin A in stage IV colorectal cancer. Gut 49: 409-417, 2001.
7. Gold E and Risbridger G: Activins and activin antagonists in the prostate and prostate cancer. Mol Cell Endocrinol 359: 107-112, 2012.

8. Loumaye A, de Barsy M, Nachit M, Lause P, van Maanen A, Trefois P, Gruson D and Thissen JP: Circulating Activin A predicts survival in cancer patients. J Cachexia Sarcopenia Muscle 8: 768-777, 2017.

9. Seachrist DD and Keri RA: The Activin social network: Activin, inhibin and follistatin in breast development and cancer. Endocrinology 160: 1097-1110, 2019.

10. Sobral LM, Bufalino A, Lopes MA, Graner E, Salo T and Coletta RD: Myofibroblasts in the stroma of oral cancer promote tumorigenesis via secretion of activin A. Oral Oncol 47: 840-846, 2011.

11. Bufalino A, Cervigne NK, de Oliveira CE, Fonseca FP, Rodrigues PC, Macedo CC, Sobral LM, Miguel MC, Lopes MA, Paes Leme AF, et al: Low miR-143/miR-145 cluster levels induce activin A overexpression in oral squamous cell carcinomas, which contributes to poor prognosis. PLoS One 10: e0136599, 2015.

12. Kelner N, Rodrigues PC, Bufalino A, Fonseca FP, Santos-Silva AR, Miguel MC, Pinto CA, Leme AF, Graner E, Salo T, et al: Activin A immunoexpression as predictor of occult lymph node metastasis and overall survival in oral tongue squamous cell carcinoma. Head Neck 37: 479-486, 2015.

13. Maeshima K, Maeshima A, Hayashi Y, Kishi S and Kojima I: Crucial role of activin a in tubulogenesis of endothelial cells induced by vascular endothelial growth factor. Endocrinology 145: 3739-3745, 2004.

14. Wagner K, Peters M, Scholz A, Benckert C, Ruderisch HS, Wiedenmann B and Rosewicz S: Activin A stimulates vascular endothelial growth factor gene transcription in human hepatocellular carcinoma cells. Gastroenterology 126: 1828-1843, 2004.

15. Bashir M, Damineni S, Mukherjee G and Kondaiah P: Activin-A signaling promotes epithelial-mesenchymal transition, invasion, and metastatic growth of breast cancer. NPJ Breast Cancer 1: $15007,2015$.

16. Panopoulou E, Murphy C, Rasmussen H, Bagli E, Rofstad EK and Fotsis T: Activin A suppresses neuroblastoma xenograft tumor growth via antimitotic and antiangiogenic mechanisms. Cancer Res 65: 1877-1886, 2005.

17. Krneta J, Kroll J, Alves F, Prahst C, Sananbenesi F, Dullin C, Kimmina S, Phillips DJ and Augustin HG: Dissociation of angiogenesis and tumorigenesis in follistatin- and activin-expressing tumors. Cancer Res 66: 5686-5695, 2006.

18. Kaneda H, Arao T, Matsumoto K, De Velasco MA, Tamura D, Aomatsu K, Kudo K, Sakai K, Nagai T, Fujita Y, et al: Activin A inhibits vascular endothelial cell growth and suppresses tumour angiogenesis in gastric cancer. Br J Cancer 105: 1210-1217, 2011.

19. Sawazaki-Calone I, Rangel A, Bueno AG, Morais CF, Nagai HM, Kunz RP, Souza RL, Rutkauskis L, Salo T, Almangush A, et al: The prognostic value of histopathological grading systems in oral squamous cell carcinomas. Oral Dis 21: 755-761, 2015.

20. Agostini M, Almeida LY, Bastos DC, Ortega RM, Moreira FS, Seguin F, Zecchin KG, Raposo HF, Oliveira HC, Amoêdo ND, et al: The fatty acid synthase inhibitor orlistat reduces the growth and metastasis of orthotopic tongue oral squamous cell carcinomas. Mol Cancer Ther 13: 585-595, 2014.

21. Livak KJ and Schmittgen TD: Analysis of relative gene expression data using real-time quantitative PCR and the 2(-Delta Delta C(T)) Method. Methods 25: 402-408, 2001.

22. Salo T, Sutinen M, Hoque Apu E, Sundquist E, Cervigne NK, de Oliveira CE, Akram SU, Ohlmeier S, Suomi F, Eklund L, et al: A novel human leiomyoma tissue derived matrix for cell culture studies. BMC Cancer 15: 981, 2015.

23. De Palma M, Biziato D and Petrova TV: Microenvironmental regulation of tumour angiogenesis. Nat Rev Cancer 17: 457-474, 2017.

24. Chang KP, Kao HK, Liang Y, Cheng MH, Chang YL, Liu SC, Lin YC, Ko TY, Lee YS, Tsai CL, et al: Overexpression of activin A in oral squamous cell carcinoma: Association with poor prognosis and tumor progression. Ann Surg Oncol 17: 1945-1956, 2010

25. Tsai CN, Tsai CL, Yi JS, Kao HK, Huang Y, Wang CI, Lee YS and Chang KP: Activin A regulates the epidermal growth factor receptor promoter by activating the PI3K/SP1 pathway in oral squamous cell carcinoma cells. Sci Rep 9: 5197, 2019.

26. Togashi Y, Kogita A, Sakamoto H, Hayashi H, Terashima M, de Velasco MA, Sakai K, Fujita Y, Tomida S, Kitano M, et al: Activin signal promotes cancer progression and is involved in cachexia in a subset of pancreatic cancer. Cancer Lett 356 (2 Pt B): 819-827, 2015. 
27. Hoda MA, Rozsas A, Lang E, Klikovits T, Lohinai Z, Torok S, Berta J, Bendek M, Berger W, Hegedus B, et al: High circulating activin A level is associated with tumor progression and predicts poor prognosis in lung adenocarcinoma. Oncotarget 7: 13388-13399, 2016.

28. Jueckstock J, Burkhardt N, Kuhn C, Blankenstein T, Mahner S, Schindlbeck C, Janni W, Rack B and Mylonas I: Expression of activin during and after chemotherapy in peripheral blood of patients with primary breast cancer. Anticancer Res 36: 2153-2159, 2016.

29. Staudacher JJ, Bauer J, Jana A, Tian J, Carroll T, Mancinelli G, Özden Ö, Krett N, Guzman G, Kerr D, et al: Activin signaling is an essential component of the TGF- $\beta$ induced pro-metastatic phenotype in colorectal cancer. Sci Rep 7: 5569, 2017.

30. Hayashi Y, Maeshima K, Goto F and Kojima I: Activin A as a critical mediator of capillary formation: Interaction with the fibroblast growth factor action. Endocr J 54: 311-318, 2007.

31. Kalli M, Mpekris F, Wong CK, Panagi M, Ozturk S, Thiagalingam S, Stylianopoulos T and Papageorgis P: Activin A signaling regulates IL13R $\alpha 2$ expression to promote breast cancer metastasis. Front Oncol 9: 32, 2019.

32. Donovan P, Dubey OA, Kallioinen S, Rogers KW, Muehlethaler K, Müller P, Rimoldi D and Constam DB: Paracrine activin-A signaling promotes melanoma growth and metastasis through immune evasion. J Invest Dermatol 137: 2578-2587, 2017.

33. McCarthy SA and Bicknell R: Inhibition of vascular endothelial cell growth by activin-A. J Biol Chem 268: 23066-23071, 1993.

34. Schramm A, von Schuetz V, Christiansen H, Havers W, Papoutsi M, Wilting $\mathrm{J}$ and Schweigerer L: High activin A-expression in human neuroblastoma: Suppression of malignant potential and correlation with favourable clinical outcome. Oncogene 24: 680-687, 2005.

35. Merfeld-Clauss S, Lu H, Wu X, March KL and Traktuev DO Hypoxia-induced activin A diminishes endothelial cell vasculogenic activity. J Cell Mol Med 22: 173-184, 2018.

36. Fahmy-Garcia S, Farrell E, Witte-Bouma J, Robbesom-van den Berge I, Suarez M, Mumcuoglu D, Walles H, Kluijtmans SGJM, van der Eerden BCJ, van Osch GJVM, et al: Follistatin effects in migration, vascularization, and osteogenesis in vitro and bone repair in vivo. Front Bioeng Biotechnol 7: 38, 2019.

37. Kang HY, Huang HY, Hsieh CY, Li CF, Shyr CR, Tsai MY, Chang C, Chuang YC and Huang KE: Activin A enhances prostate cancer cell migration through activation of androgen receptor and is overexpressed in metastatic prostate cancer. J Bone Miner Res 24: 1180-1193, 2009

38. Tahergorabi $\mathrm{Z}$ and Khazaei $\mathrm{M}$ : A review on angiogenesis and its assays. Iran J Basic Med Sci 15: 1110-1126, 2012.
39. Levchenko T, Veitonmäki N, Lundkvist A, Gerhardt H, Ming Y, Berggren K, Kvanta A, Carlsson R and Holmgren L: Therapeutic antibodies targeting angiomotin inhibit angiogenesis in vivo. FASEB J 22: 880-889, 2008

40. Douglass S, Goyal A and Iozzo RV: The role of perlecan and endorepellin in the control of tumor angiogenesis and endothelial cell autophagy. Connect Tissue Res 56: 381-391, 2015.

41. Li Y, Zhu H, Klausen C, Peng B and Leung PC: Vascular endothelial growth factor-A (VEGF-A) mediates activin A-induced human trophoblast endothelial-like tube formation. Endocrinology 156: 4257-4268, 2015.

42. Schuster C, Akslen LA, Stokowy T and Straume O: Predictive value of angiogenic proteins in patients with metastatic melanoma treated with bevacizumab monotherapy. J Pathol Clin Res 5: 53-62, 2019.

43. Caporarello N, Lupo G, Olivieri M, Cristaldi M, Cambria MT, Salmeri M and Anfuso CD: Classical VEGF, Notch and Ang signalling in cancer angiogenesis, alternative approaches and future directions (Review). Mol Med Rep 16: 4393-4402, 2017.

44. Vempati P, Popel AS and Mac Gabhann F: Extracellular regulation of VEGF: Isoforms, proteolysis, and vascular patterning. Cytokine Growth Factor Rev 25: 1-19, 2014.

45. Zhao SF, Yang XD, Lu MX, Sun GW, Wang YX, Zhang YK, $\mathrm{Pu}$ YM and Tang EY: Prognostic significance of VEGF immunohistochemical expression in oral cancer: A meta-analysis of the literature. Tumour Biol 34: 3165-3171, 2013.

46. Cai C, Böttcher MC, Werner JA and Mandic R: Differential expression of VEGF121, VEGF165 and VEGF189 in angiomas and squamous cell carcinoma cell lines of the head and neck. Anticancer Res 30: 805-810, 2010.

47. Ehrbar M, Djonov VG, Schnell C, Tschanz SA, Martiny-Baron G, Schenk U, Wood J, Burri PH, Hubbell JA and Zisch AH: Cell-demanded liberation of VEGF121 from fibrin implants induces local and controlled blood vessel growth. Circ Res 94: 1124-1132, 2004.

48. Nakatsu MN, Sainson RC, Pérez-del-Pulgar S, Aoto JN, Aitkenhead M, Taylor KL, Carpenter PM and Hughes CC: $\operatorname{VEGF}(121)$ and $\operatorname{VEGF}(165)$ regulate blood vessel diameter through vascular endothelial growth factor receptor 2 in an in vitro angiogenesis model. Lab Invest 83: 1873-1885, 2003.

49. Tozer GM, Kanthou C and Baguley BC: Disrupting tumour blood vessels. Nat Rev Cancer 5: 423-435, 2005.

50. Shang B, Cao Z and Zhou Q: Progress in tumor vascular normalization for anticancer therapy: Challenges and perspectives. Front Med 6: 67-78, 2012

51. Goel S, Duda DG, Xu L, Munn LL, Boucher Y, Fukumura D and Jain RK: Normalization of the vasculature for treatment of cancer and other diseases. Physiol Rev 91: 1071-1121, 2011. 